\title{
DO LITISCONSÓRCIO: BASES FUNDAMENTAIS PARA ENTENDIMENTO DO MECANISMO
}

Andreas Gabriel Ferreira Miranda

Universidade do Oeste Paulista - UNOESTE, Curso de Direito, Presidente Prudente, SP. E-mail: andreasferreira50@gmail.com

\begin{abstract}
RESUMO
O litisconsórcio é baseado na existência de três ou mais sujeitos na relação processual, sendo mais de um autor, ou réu, não ficando o litisconsórcio restrito apenas as relações processuais, sendo cabível tanto em incidentes processuais, nos casos de conflito de competência e, até mesmo, em recursos, há varias possibilidades de formação litisconsorciais podendo ser: necessário, unitário, passivo, ativo, misto, facultativo não esquecendo da possibilidade de intervenção "iussu iudicis". 0 mecanismo do litisconsórcio traz mais celeridade as ações judiciais, tornando causas que poderiam ser de grande morosidade ao sistema de adjudicação, mais rapidez e eficiência em suas resoluções, tornando o princípio da celeridade processual mais eficiente, além de desatolar o sistema judiciário.
\end{abstract}

Palavras-chave: Direito Processual Civil. Litsconsórcio. Relação Processual. Pluralidade.

OF LITISCONSORRIA: FUNDAMENTAL BASIS FOR UNDERSTANDING THE MECHANISM

\begin{abstract}
The joinder is based on the existence of three or more subjects in the procedural relationship, being more than one author, or defendant, the joinder is not restricted only procedural relationships, being applicable in both procedural incidents, in cases of conflict of jurisdiction and, until even in resources, there are several possibilities for litisconsortial training, which may be: necessary, unitary, passive, active, mixed, optional, not forgetting the possibility of "iussu iudicis" intervention. The mechanism of litigation brings more speed to judicial proceedings, making causes that could be very slow to the system of adjudication, more speed and efficiency in its resolutions, making the principle of procedural speed more efficient, in addition to untangling the judicial system.
\end{abstract}

Keywords: Civil Procedural Law. Joinder. Processual Relationship. Plurality. 


\section{INTRODUÇÃO}

O litisconsórcio fundamentalmente é a existência de vários sujeitos em um dos polos de uma relação processual, nas palavras de Fredie Didier (2016, p.457): "há litisconsórcio quando houver mais de um autor ou mais de um réu". Não sendo necessário que seja apenas uma relação processual, sendo cabível tal mecanismo em conflitos de competência, como na fase recursal.

Há uma variedade de possibilidades de formação de um litisconsórcio, como a possibilidade de existência de litisconsórcio até mesmo diante da cumulação de pedidos, podendo haver cumulação e conexão diante da afinidade de causas ou autores. (DIDIER, 2016, p. 457-475)

Por sua vastidão de possibilidades a existência desse mecanismo torna-se uma importante forma de efetivar a celeridade processual e o tempo razoável de duração do processo, além de, desatolar o sistema judiciário.

Após curta reflexão, o presente trabalho, denominado Do Litisconsórcio: Espécies Litisconsorciais, tem por objetivo analisar a importância do mecanismo de formação litisconsorcial, demonstrando a importância jurídica e acadêmica do mecanismo diante da morosidade judiciaria, atentando a forma de facilitar e diminuir o numero de demandas no judiciário, suscitando um aprofundamento e trazendo a importância da efetivação e utilização desse aparato processual para melhoria do sistema judiciário . A pesquisa será elaborada por meio de pesquisas teóricas dos fatos em tela, abordando diplomas legais existentes, a jurisprudência e a doutrina sobre o fato narrado.

\section{MÉTODO}

O presente estudo seguirá o método exploratório, com emprego de pesquisa à legislação, doutrina e jurisprudência acerca do instrumento do litisconsórcio, abordando a sistemática processual na qual ela se sustenta, com ênfase nos problemas para a formação e enquadramento, e ainda exaustivamente por meio da dedução dialética chegar a um fator onde o litisconsórcio se mostre sistema que facilita o bom funcionamento do sistema judiciário.

\section{GENERALIDADES}

O litisconsórcio pode ser diversificado em ativo ou passivo, dependendo do polo processual em que ele se constituir, falamos em litisconsórcio ativo quando este é formado no lado autor da demanda judicial, e passivo quando este se forma na associação de réus. Ainda podemos considera-lo misto, quando ambos os polos houverem associados no interesse em lide. (DIDIER, 2016, p. 457).

Quanto ao tempo de formação do litisconsórcio pode ser classificado em inicial e ulterior, sendo o inicial formado contemporaneamente a ação ou incidente processual, por ser postulado por mais de uma pessoa. Já no caso de formação após a postulação da ação ou incidente, recebe o nome de litisconsórcio ulterior, considerado como uma excepcionalidade. Fredie Didier (2016, p.458) classifica o surgimento do litisconsórcio ulterior em três hipóteses "a) em razão de uma intervenção de terceiro [...]b) pela sucessão processual; c) pela conexão ou continência".

\section{DISCIPLINA DO LITISCONSÓRCIO}

Constituindo o fenômeno do litisconsórcio uma pluralidade de sujeitos parciais dentro da relação jurídica, a disciplina legal dele baseia-se fundamentalmente em dois aspectos: "o primeiro diz respeito a sua constituição, à sua admissibilidade e até à eventual necessidade[...] o segundo é atinente Às relações entre os litisconsortes, uma vez constituído o litisconsórcio ".(CITRA, GRINOVER, DINAMARCO, 2015, p.390). 


\section{DO LITISCONSÓRCIO SIMPLES E UNITÁRIO}

A divisão do litisconsórcio mediante analise de objeto de litigio dentro do procedimento recebe-se o nome de litisconsórcio unitário, será comprovada a existência de um litisconsórcio unitário sempre que o provimento jurisdicional de mérito for sobre situações semelhantes e uniformes, julgando a ação a decisão e julgamento será uniforme para todos. "litisconsórcio unitário é a unidade da pluralidade: vários são considerados um; o litisconsórcio unitário não é o que parece ser, pois várias pessoas são tratadas no processo como se fossem apenas uma." (DIDIER, 2016)

Quando o a decisão do litisconsórcio puder ser diferente para cada um dos associados, fala-se em litisconsórcio simples (ORTEGA, 2016). Mesmo havendo mera possibilidade de a decisão ser diferente já configura litisconsórcio simples.

\section{DO LITISCONSÓRCIO NECESSÁRIO E FACULTATIVO}

Haverá essa espécie litisconsorcial sempre que houver obrigação em sua formação, tem o nome de necessário pois sua formação é fundamental e indispensável, quer seja pela natureza da relação jurídica ou imposição legal. "Art.114 CPC - o litisconsórcio será necessário por disposição de lei ou quando, pela natureza da relação controvertida, a eficácia da sentença depender da citação de todos que devam ser litisconsortes". (BRASIL, 2016). A nomenclatura do fenômeno litisconsorcial define, via de regra, a sua forma e obrigação de existência.

Dentro do litisconsórcio necessário há possibilidade de formação tanto ativa ou passivamente.

O litisconsórcio facultativo e aquele que da ao autor a faculdade de sua formação, "é facultativo o litisconsórcio cuja formação não é obrigatória, apesar de admitido como medida de economia processual ou para evitar decisões conflitantes". (SÁ, 2012, p.84)

\section{JULGAMENTO DO LITISCONSÓRCIO NECESSÁRIO}

No litisconsórcio necessário o cabimento de requerer a citação de todos os litisconsortes necessário é dado ao autor, não o fazendo o magistrado devera conceder prazo para que este o faça, sendo vedado ao juiz a expedição de citação de oficio, visto que se o fizer rompe-se o princípio da inércia. A falta de citação de um dos litisconsortes pode acarretar uma sentença nula, quando não parcialmente ineficaz.

Há diferença dentro dos polos, quando falamos da demanda litisconsorcial dentro do polo ativo, todos devem demandar, não efetuando a demanda qualquer dos outros litisconsortes poderão promover a ação (SÁ, 2012, 85)

$\mathrm{O}$ artigo 115 do CPC, zela da natureza da sentença proferida quando ausente a citação, o referido artigo mostra a seguinte redação:

\footnotetext{
Art.115. A sentença de mérito, quando proferida sem a integração do contraditório será

l- Nula, se a decisão deveria ser uniforme em relação a todos que deveriam ter integrado o processo;

II- Ineficaz, nos outros casos, apenas para os que não foram citados. (BRASIL, 2015)
}

Diante da redação do referido artigo sobre a ineficácia da sentença, há também a nulidade, sendo assim, não a apenas ineficácia, mas o ato torna-se nulo e por ser nulo fica ineficaz. De todo modo somente aquele litisconsorte que foi preterido teria a legitimidade de reconhecer a ineficácia ou nulidade da sentença feita sem sua citação (DIDIER,2016, P.471).

\section{COISA JULGADA NO LITISCONSÓRCIO FACULTATIVO UNITÁRIO}

Como tratado em título anterior, o litisconsórcio facultativo e aquele que faculta a sua formação ao autor da demanda litisconsorcial, nesse caso deve-se analisar a colegitimação se esta é passiva ou ativa. 
Sendo a colegitimação passiva, e houver unitariedade, o litisconsórcio necessário será imposto sem nenhum problema "como ninguém pode se recusar a ser réu, o litisconsórcio formarse-á independentemente da vontade dos litisconsortes" (DIDIER, 2016, p.474).

Tratando-se de colegitimação ativa, havendo unitariedade poderá qualquer dos Co legitimados a propor a demanda de maneira individual, tornando um possível litisconsórcio unitário.

Fredie Didier (2016) explica a existência de três correntes para a formação e existência de coisa julgada dentro do litisconsórcio facultativo unitário:

a) como os casos dos litisconsórcios facultativo unitário são, rigorosamente, casos de legitimação extraordinária, pois alguém está autorizado a, em nome próprio levar a juízo uma situação jurídica que não the pertence[...] ou que não the pertence exclusivamente[...] a coisa julgada estendera os seus efeitos ao demais co legitimados[...] hipótese de extensão 'ultra partes' dos efeitos da coisa julgada mitigando a regra do art.506 do CPC.

b) [...] extensão subjetiva da coisa julgada secundum eventum lits. Assim a coisa julgada somente se estenderia aos demais titulares do direito se fosse para beneficiar[..]

c) Em nenhuma hipótese haverá a extensão subjetiva da coisa julgada[...]

Com a atual legislação a terceira corrente proposta torna-se obsoleta, visto que hoje e possível a extensão da coisa julgada favorável a terceiro.

\section{TRATAMENTO DOS LITISCONSÓRCIOS}

E importante saber a forma como se forma o litisconsórcio para que se consiga entender o relacionamento e a reciproca entre os litisconsortes. No caso do tratamento uniforme, nota-se que a formação do litisconsórcio se deu através de unitariedade. Havendo distinção de tratamento, sabe-se que a formação do litisconsórcio ocorreu de forma simples.

Para entender a conduta de cada litisconsorte a uma diversificação em conduta determinante e alternativa. Considera-se determinante a conduta da parte que leva a uma situação desfavorável. A alternativa é aquela onde a parte busca uma melhor situação processual. (DIDIER, 2016, p. 474)

Referente ao tratamento pelo principio da comunhão de provas, as provas não pertencem aos Co legitimados, mas sim ao processo, sendo assim, a prova produzida por um litisconsorte simples poderá ser aproveitada pelos demais, é o que define o Art. 371. "O juiz apreciará a prova constante dos autos, independentemente do sujeito que a tiver promovido, e indicará na decisão as razões da formação de seu convencimento." (BRASIL, 2018)

A conduta determinante de um dos litisconsortes não poderá prejudicar outro litisconsorte independente do regime do litisconsórcio explicitando a eficácia das condutas determinantes para o tratamento igualitário dos litisconsortes.

\section{CONCLUSÃO}

Conclui-se que o mecanismo do litisconsórcio é uma forma eficaz de resguardo de direitos, diminuição da morosidade processual, e atolamento de demandas repetitivas. Quando integrado a um litisconsórcio, obtêm-se a garantia de uniformidade, quando for o tipo que prevê uniformidade nas decisões, e até mesmo decisões diferentes para cada um dos litisconsortes.

O litisconsórcio sem duvidas se mostra um potente diminuidor de demandas no sistema judiciário, além de ser um facilitador na aquisição de direitos dos litigantes diante de suas demandas.

A melhoria do sistema judiciário fara com que o litisconsórcio seja de formação mais simplificada com isso haverá melhoria na sua formação e resolução. Para que isso ocorra deve se observar a base de formação, forma de tratamento dos colegitimados, além da busca pela compreensão da extenção da coisa julgada ao final do procedimento. 


\section{REFERÊNCIAS}

BRASIL. Novo Código de Processo Civil. Coordenação Flavia Alves Bravin. 25. Ed. São Paulo: Saraiva, 2018

CITRA, A.C.A; GRINOVER, A. P; DINAMARCO, C. R; Teoria geral do processo. 31. Ed. São Paulo: Malheiros, 2015.

DIDIER, Fredie Jr. Curso de direito processual civil. V.1. 18. Ed. São Salvador: Juspodivim, 2016.

ORTEGA, Flavia Teixeira, O litisconsórcio no novo CPC. 19/10/16. Disponível em: <https://draflaviaortega.jusbrasil.com.br/noticias/396198506/o-litisconsorcio-no-novo-cpc>. Acessado em: 01/08/2018.

SÁ, Renato de., FREIRE, Rodrigo da Lima. Processo civil I: teoria geral do processo. 1. Ed. São Paulo: Saraiva, 2012. 